\title{
Música nas escolas públicas municipais do Rio Grande do Sul
}

\author{
CRISTINA ROLIM WOLFFENBÜTTEL
}

Universidade Estadual do Rio Grande do Sul, Montenegro, RS, Brasil

RESUMO

Esta pesquisa investigou a música nas escolas públicas municipais do Rio Grande do Sul. Teve como desenho metodológico a abordagem quantitativa, o método survey interseccional de grande porte e a aplicação de questionários autoadministrados como técnica de coleta de dados. A análise de conteúdo constituiu a técnica para a análise dos dados, valendo-se de conceitos da educação musical balizados pela legislação educacional e pela abordagem do ciclo de políticas. Como resultados, constatou-se que, apesar da legislação vigente e da existência de algumas atividades musicais nas escolas, ainda persiste a luta para a efetiva implementação da educação musical no estado.

\section{PALAVRAS-CHAVES}

música nas escolas; Rio Grande do Sul; políticas públicas em educação musical; lei federal n. 11.769/2008. 


\section{MUSIC IN MUNICIPAL PUBLIC SCHOOLS OF RIO GRANDE DO SUL}

\section{ABSTRACT}

This research investigated music in municipal public schools of Rio Grande do Sul. The methodological design used included a quantitative approach, an intersectional survey method at large scale, and self-administered questionnaires for collecting data. In order to analyze the data, a content analysis was performed, taking as reference concepts of music education based on education legislation and the policy cycle approach. As a result, it was found that in spite of the applicable law and the existence of some music activities in schools, there is still a struggle for effectively implementing music education in the state.

\section{KEYWORDS}

music in schools; Rio Grande do Sul; public policies on music education; federal law n. $11.769 / 2008$.

\section{MÚSICA EN LAS ESCUELAS PÚBLICAS MUNICIPALES DE RIO GRANDE DO SUL}

\section{RESUMEN}

Esta investigación analizó la forma en que se enseña música en las escuelas públicas municipales de Rio Grande do Sul. El diseño metodológico utilizado incluyó un enfoque cuantitativo, un método de encuesta intersectorial a gran escala y cuestionarios autoadministrados como técnica de recolección de datos. Con el fin de analizar estos datos, se llevó a cabo un análisis de contenido, a partir de los conceptos de educación musical con base en la legislación educativa y en el enfoque del ciclo de políticas. Como resultados, se observó que, a pesar de la legislación vigente y de la existencia de algunas actividades musicales en las escuelas, aún continúa la lucha para que la educación musical se implemente de manera eficaz en el estado.

\section{PALABRAS CLAVE}

música en las escuelas; Rio Grande do Sul; políticas públicas sobre educación musical; ley federal n. 11.769/2008. 


\section{INTRODUÇÃO}

O histórico da educação musical no Brasil é longo. Conforme Lemos Júnior (2012), os primeiros indícios coincidem com o descobrimento. Com a vinda da família real, em 1808, o acesso à música foi ampliado. Porém, mesmo presente desde o descobrimento, a música só foi oficialmente instituída nas escolas no ano de 1854, sendo que a formação específica do professor de música foi exigida apenas em 1890.

A partir de 1920, com a Escola Nova, algumas contribuições favoreceram a expansão do ensino de música no país, destacando-se o canto orfeônico de Villa-Lobos (Lemos Júnior, 2012). As reformas realizadas no ensino brasileiro em 1931 e em 1942 oportunizaram a expansão do canto orfeônico, tornando sua presença obrigatória no ensino primário e ginasial. Posteriormente, o início da ditadura militar, em 1964, tornou necessária uma adequação à educação brasileira como um todo, modificando o nome canto orfeônico para educação musical. Em 1971, o ensino de música foi extinto dos currículos escolares, sendo denominado educação artística e mantendo um caráter interdisciplinar, com ênfase em artes plásticas, dança, música e teatro (Lemos Júnior, 2012).

Nessa época, a Lei de Diretrizes e Bases da Educação Nacional n. 5.692, de 1971 (LDB n. 5.692/1971), instituiu a educação artística no ensino fundamental e médio de todo o país (Brasil, 1971). Conforme Fusari e Ferraz (1992, p. 15-16), com a inclusão da educação artística no currículo escolar, por meio da LDB n. 5.692/1971:

houve uma tentativa de melhoria no ensino de Arte na educação escolar, ao incorporar atividades artísticas com ênfase no processo expressivo e criativo dos alunos. Com essas características, passou a compor um currículo que propunha valorização da tecnicidade e profissionalização em detrimento da cultura humanística e científica predominantemente anteriores. Paradoxalmente, a Educação Artística apresentava, na sua concepção, uma fundamentação de humanidade dentro de uma lei que resultou mais tecnicista.

Com a LDB n.5.692/1971, os conteúdos específicos das linguagens artísticas, principalmente a música, foram esvaziados em prol de uma educação dita polivalente. Para Hentschke e Oliveira (2000), na década de 1970 predominava a tendência educacional cuja ênfase apresentava-se mais no aspecto expressivo dos indivíduos.

A respeito da política educacional para o ensino das artes no ensino fundamental e médio da educação básica, Penna (2004a, 2004b) empreendeu uma investigação que analisou os documentos oficiais e as suas implicações para as práticas escolares. A pesquisadora analisou a legislação e os termos normativos do ensino de música apontando as continuidades e as modificações ocorridas entre as décadas de 1970 e 1990 (Penna, 2004a). Penna discutiu a política educacional para o ensino das artes com base na análise da LDB n. 5.692/1971 (Brasil, 1971) e, posteriormente, do parecer do Conselho Federal de Educação n. 1.284, de 1973 (Brasil, 1973). Esse parecer propunha o ensino das artes na educação básica em uma perspectiva integrada, na proposta de polivalência dos professores quanto às artes plásticas, artes cênicas, música e desenho. Segundo Penna (2004a), não havia 
uma definição clara no texto da LDB n. 5.692/1971 a respeito de quais linguagens artísticas deveriam ser contempladas.

Posteriormente, o parecer do Conselho Federal de Educação n. 540, de 1977 (Brasil, 1977b), apontou uma inadequação de enfoque na área, ocorrida em anos anteriores, afirmando que, nessa época, o ensino de música centrava-se apenas na teoria musical e na prática do canto coral, sendo que o ensino da educação artística não mais comportaria tais abordagens. A música, portanto, encontrava-se no campo da educação artística.

Ao longo dos anos, tentou-se tornar específicos os preceitos normativos para o ensino de música, evidenciado nos pareceres do Conselho Federal de Educação dos anos de 1973 e 1977 (Penna, 2004a, p. 21). A Lei de Diretrizes e Bases da Educação Nacional n. 9.394, de 1996 (LDB n. 9.394/1996), é também resultado da busca pela separação no ensino das artes na educação básica (Brasil, 1996).

Apesar de a LDB n. 9.394/1996 estabelecer o ensino das artes como componente curricular obrigatório nos diversos níveis da educação básica, persistiram indefinições e ambiguidades (Penna, 2004a), permitindo múltiplas possibilidades e interpretações (Brasil,1996). A partir da LDB n. 9.394/1996, pesquisadores lutaram para separar as áreas das artes no ensino escolar. A despeito das mudanças pelas quais passou a legislação, na prática o ensino ainda continuava nominado como educação artística. Os estudos e as pesquisas, desde então, têm investigado o ensino de música escolar e as políticas públicas para o ensino de música na educação básica (Del Ben, 2005; Diniz, 2005; Penna, 2002,2004a, 2004b; Queiroz,2012; Queiroz e Penna, 2012; Requião, 2013; Santos, 2005; Souza et al., 2002; Wolffenbüttel, 2014). Mesmo com tentativas para garantir a presença do ensino de música na educação básica, as políticas mais recentes não têm conseguido legitimar esse esforço, resultando, na prática, na escassa presença de professores de música atuando na educação básica (Ahmad, 2011; Del Ben, 2005; Penna, 2002, 2004a, 2004b; Santos, 2005; Wolffenbüttel, 2011; Wolffenbüttel e Silva, 2014).

Com a lei n. 11.769, de 2008 (Brasil, 2008), que dispõe sobre a obrigatoriedade do ensino da música na educação básica, o panorama legal para a inserção da música nas escolas recebeu um incremento. Conforme a lei, a inserção da música deveria entrar em vigor na data de sua publicação, em 19 de agosto de 2008, e os sistemas de ensino teriam três anos letivos para se adaptarem às exigências estabelecidas, ou seja, em 2011. Passaram-se os anos e observou-se que muitas das secretarias de educação do país não implementaram o ensino de música nas escolas.

Em 2013, o Conselho Nacional de Educação (CNE) realizou diversas audiências públicas, em parceria com a Associação Brasileira de Educação Musical $(\mathrm{ABEM})$, com vistas a discutir o assunto com a sociedade e construir possibilidades de resolução. Essas ações resultaram no parecer CNE/CEB n. 12/2013 (Brasil, 2013), aprovado em 4 de dezembro de 2013. Essas ações do CNE produziram efeitos em alguns municípios brasileiros. No Rio Grande do Sul observou-se a movimentação de algumas prefeituras que lançaram editais de concursos para o provimento de vagas de professor de música nas escolas de suas redes de ensino. Não obstante, essas ações ainda não foram suficientes para a efetiva inserção da música nas escolas. 
Partindo dos pressupostos até aqui apresentados e considerando o respaldo da legislação em educação vigente no Brasil, surgiram questionamentos em relação à inserção da música nas escolas públicas municipais do Rio Grande do Sul. Esses questionamentos apresentam-se do seguinte modo: Quantas secretarias municipais de educação do Rio Grande do Sul implementam a música nas escolas de suas redes de ensino? Quantas e quais secretarias municipais de educação do estado ofertam atividades musicais? Quais são as ações de inserção da música nas escolas? Quem desenvolve atividades musicais nas escolas públicas municipais? Quantas e quais secretarias municipais de educação promoveram concursos para professores de música? Quantas e quais secretarias municipais de educação possuem professores de música concursados em suas redes de ensino? Esta pesquisa, portanto, objetivou investigar a presença da música em escolas públicas municipais do Rio Grande do Sul.

\section{CAMINHOS METODOLÓGICOS}

A metodologia desta pesquisa foi fundamentada pelo uso da abordagem quantitativa, do método survey (Babbie, 1999; Cohen e Manion, 1994) e pela aplicação de questionários autoadministrados como técnica para a coleta dos dados (Laville e Dionne, 1999).

A coleta dos dados ocorreu por meio de contatos estabelecidos com as secretarias municipais de educação dos 497 municípios que compõem o Rio Grande do Sul via correio eletrônico. Nesses contatos foram encaminhados documentos, sendo estes uma carta apresentando a pesquisa e a equipe executora, bem como um questionário.

O questionário encaminhado às secretarias municipais de educação configurou-se do tipo misto (Markoni e Lakatos, 2005). Formado por doze questões de respostas abertas e fechadas, o questionário inquiria as secretarias municipais de educação a respeito da oferta de atividades musicais nas escolas, das atividades musicais existentes nas escolas, da promoção de concursos públicos para professores de música, da presença de professores de música nas escolas e sobre os profissionais que desenvolvem atividades musicais nas escolas. Esse questionário foi enviado às secretarias municipais de educação do Rio Grande do Sul, solicitado seu preenchimento e posterior retorno via e-mail. De posse dos questionários respondidos, procedeu-se à análise de conteúdo, trilhando as etapas de preparação das informações, unitarização, categorização, descrição e interpretação (Moraes, 1999).

Com os dados coletados por meio dos questionários autoadministrados, o passo seguinte foi o processo de preparação, identificando amostras de informação a serem analisadas. Esse procedimento ocorreu a partir da leitura dos dados no todo, selecionando quais estavam de acordo com os objetivos da pesquisa. Devidamente preparados, os dados passaram pela unitarização, por meio da leitura de todo o material e definição da unidade de análise. Em seguida, o material foi relido, sendo identificadas as unidades de análise e codificando-as, passando-se à categorização. Esses procedimentos prepararam a descrição. Definidas as categorias e identificado o material de cada uma delas, passou-se à comunicação dos resultados, 
cuja descrição é o primeiro momento. Para cada categoria foi produzido um texto-síntese inicial sobre a música nas escolas de cada município. Esse procedimento subsidiou a interpretação (Moraes, 1999).

Por fim, realizou-se a interpretação, fundamentada na literatura especializada e demais experiências da investigação, além daquelas vividas durante a pesquisa. Foi constituída de duas vertentes; uma delas, formada pela fundamentação teórica em educação musical (Kraemer, 2000) e pela análise das políticas - notadamente relacionada à abordagem do ciclo de políticas (Ball, 1994; Bowe et al., 1992). A outra vertente tomou como base os dados e as categorias da análise. Os resultados e discussões emergiram dos dados e das categorias. Nesse caso, a própria construção da teoria foi a interpretação. Teorização, interpretação e compreensão constituíram-se um movimento circular em que se procurou, a cada retomada do ciclo, atingir maior profundidade na análise (Moraes, 1999). Ao final das cinco etapas, preparação, unitarização, categorização, descrição, interpretação, respondeu-se ao objetivo desta pesquisa, ou seja, sobre como ocorre a presença da música em escolas públicas municipais do Rio Grande do Sul.

\section{FUNDAMENTAÇÃO TEÓRICA}

O referencial teórico desta pesquisa fundamentou-se em conceitos de educação musical (Kraemer, 2000) balizados pela abordagem do ciclo de políticas (Ball, 1994; Bowe et al., 1992).

\section{A EDUCAÇÃO MUSICAL}

Rudolf-Dieter Kraemer, renomado professor de música e pesquisador na Alemanha, discute o campo epistemológico da educação musical refletindo sobre sua delimitação como ciência ou área do conhecimento. Em seus estudos, Kraemer (2000) trata da educação musical como um imbricamento entre disciplinas, discutindo dimensões e funções do conhecimento pedagógico-musical e salientando as particularidades da área em relação às demais disciplinas. Kraemer (2000) esclarece que a pedagogia da música se ocupa com as relações entre pessoa(s) e música(s), dividindo seu objeto de estudo com as ciências humanas. Exemplifica essas disciplinas enfocando-as quanto aos aspectos filosóficos, históricos, psicológicos, sociológicos, musicológicos, pedagógicos e de outras que possam ter um significado pedagógico-musical importante.

Os aspectos filosóficos, apontados por Kraemer (2000) incluem a estética da música e a antropologia pedagógica. Os aspectos históricos são tratados na perspectiva de que, sendo a história um conjunto de contribuições humanas, é importante que as pessoas reconstruam seus próprios acontecimentos valendo-se do material disponível, analisando-os e os interpretando criticamente. Assim, a história abrangeria a pesquisa e a escrita histórica. $\mathrm{O}$ autor salienta, nessa análise, a musicologia histórica e a pedagogia histórica.

Entre os aspectos psicológicos, Kraemer (2000) apresenta: 
1. a psicologia geral da música: recepção estética e sociológica da música, pesquisa sobre aprendizagem e motivação;

2. a psicologia da música psicológico-social: socialização musical, pesquisas sobre concepção musical e sobre comunicação;

3. a psicologia diferenciada da música: talento musical e sua medição, desenvolvimento de testes, características da personalidade e do comportamento musical;

4. e a psicologia do desenvolvimento: gênese de determinados comportamentos musicais e níveis de vivência relativos ao amadurecimento, crescimento e meio sociocultural.

Os aspectos sociológicos partem da sociologia da música, examinando efeitos da música, condições e relações sociais relacionadas à música. $\mathrm{O}$ homem é observado nas áreas institucionalizadas e organizadas da educação, incluindo "processos de socialização, instituições e formas de organização, profissão, grupos de mesma idade, meios e condições legais e econômicas” (Kraemer, 2000, p. 57).

Pedagogia da música e musicologia "unem-se no esforço comum em compreender a música”. Os aspectos musicológicos são apresentados considerando-se a pesquisa musicológica - etnomusicologia, acústica, teoria da música, entre outras áreas - tratando de uma "possível análise e interpretação global dos eventos musicais", sendo o conteúdo musical propriamente dito (Kraemer, 2000, p. 58-59). A didática da música interessar-se-ia pelos significados que as manifestações musicais poderiam adquirir no processo educacional.

Os aspectos pedagógicos tomam como base a pedagogia, que se ocupa "com teorias da educação e formação, premissas, condições, processos e consequências da ação educacional e didática, com questões sociais e institucionais, com problemas do ensino, da aprendizagem e didáticos"(Kraemer, 2000, p. 59). São apontados diferentes ramos da pedagogia como ciência da educação: pedagogia geral, pedagogia especial, pedagogia histórica, pedagogia pré-escolar, pedagogia escolar, pedagogia da família, pedagogia social, pedagogia da empresa/ profissão/economia e pedagogia comparada. Há outras disciplinas que podem apresentar um significado pedagógico-musical especial, como ciências políticas, pedagogia do esporte, pedagogia da arte, questões medicinais e de saúde, jurídicas, pedagógico-religiosas, ecológicas, econômicas, para citar algumas das possibilidades existentes (Kraemer, 2000).

Kraemer (2000) discute o entrelaçamento da pedagogia da música com outras disciplinas. Rassalta-se que uma perspectiva de entrelaçamento da pedagogia da música com outras disciplinas a considera resultante do enlace recíproco entre as disciplinas, criando uma espécie de teia. Essa concepção de entrelaçamento propõe uma dimensão alargada da pedagogia da música, com limites mais abrangentes e flexíveis.

Para Kraemer (2000, p. 61), no "centro das reflexões musicais estão os problemas da apropriação e transmissão da música”. Pedagogia e pedagogia da música não se constituem disciplinas isoladas e resultam diferentes agrupamentos da área. São disciplinas de integração orientadas na ação, conforme o objeto de pesquisa. 
Kraemer (2000, p. 66) afirma que a particularidade do saber pedagógico-musical está "no cruzamento de ideias pedagógicas marcadas pelas ciências humanas, orientadas pela cultura musical e ideias estético-musicais". Além do conhecimento sobre fatos e contextos pedagógico-musicais, também é necessário colocar à disposição os princípios de explicação da prática músico-educacional, para as decisões, orientações, esclarecimentos, influência e otimização dessas práticas,

Por fim, Kraemer (2000) propõe um modelo estrutural da pedagogia da música que inclui a análise e os campos de aplicação da área, os aspectos que a compõem - musicológicos, pedagógicos, entre outros -, além das funções da pedagogia da música - compreender e interpretar, descrever e esclarecer, conscientizar e transformar a prática músico-educacional.

\section{A ABORDAGEM DO CICLO DE POLITICAS}

Stephen Ball e Richard Bowe, pesquisadores ingleses da área de políticas educacionais, propuseram a caracterização do processo político, subsidiando a elaboração da abordagem do ciclo de políticas (Ball, 1994; Bowe et al., 1992). Para os autores, ao introduzir a noção de um ciclo contínuo de política, a pretensão é atrair a atenção para a recontextualização política que transita pelas escolas. Contudo, o panorama das pesquisas escolares requer considerar não somente um currículo nacional, mas também outros elementos que constituem a política educacional (Bowe et al., 1992). Há um ciclo composto de contextos que influenciam e são influenciados, sendo estes os contextos da influência, do texto político, da prática, dos efeitos e da estratégia política.

O contexto em que a política é iniciada é o da influência, no qual os discursos políticos são construídos e as partes interessadas lutam para influenciar as decisões. O segundo contexto, do texto político, constitui-se de textos representativos da política. Essas representações podem se apresentar como textos jurídicos, documentos oficiais orientadores, comentários formais ou informais, discursos, apresentações públicas de políticos e funcionários importantes, vídeos oficiais, entre outras representações (Bowe et al., 1992). Políticas são, portanto, intervenções textuais; contudo, também carregam consigo limitações e possibilidades. A resposta a esses textos tem consequências reais, sendo experienciadas no contexto da prática por aqueles a quem a política se dirige. A política não é simplesmente recebida e implementada, mas está sujeita à interpretação, podendo ser recriada. $\mathrm{E}$ as pessoas que executam as políticas não se confrontam ingenuamente com os textos políticos (Bowe et al.,1992).

Posteriormente, Stephen Ball (1994) expandiu a teoria, acrescentando outros dois contextos: o contexto dos efeitos e o contexto da estratégia política. O contexto dos efeitos preocupa-se com as questões de justiça, igualdade e liberdade individual. Os efeitos das políticas apresentam-se como gerais e específicos. Os efeitos gerais de uma política são quando aspectos próprios da mudança e conjuntos de respostas - que se apresentam no contexto da prática — são agrupados e analisados. Esses efeitos são, por vezes, negligenciados em estudos mais particularizados em relação às mudanças ou à textos políticos como determinantes do impacto na prática. Se analisados isoladamente, os efeitos específicos podem parecer limitados. Ball sugere, então, que a análise de uma política envolva o exame dessas duas 
dimensões, bem como das interfaces da política em estudo com outras políticas setoriais e com o conjunto das políticas. Por fim, o contexto da estratégia política envolve a identificação de um conjunto de atividades sociais e políticas necessárias para o trato com as desigualdades originadas pela política em estudo. Esse componente é essencial para a pesquisa social crítica, e esse trabalho é produzido para uma utilização estratégica em embates e situações sociais específicas (Ball, 1994).

Ball (1994) postula a necessidade de desvincular as teorias em política educacional dos trabalhos do Estado. A política é uma "economia de poder", um conjunto de tecnologias e práticas, cujas realizações e lutas ocorrem acima dos arranjos locais. Política é, ao mesmo tempo, texto e ação, palavras e contratos; isso é o que se representa e o que se pretende. Políticas são sempre incompletas, básicas e simples. A prática, todavia, é sofisticada, contingente, complexa e instável. A política como prática é criada em uma "trialética" de dominação, resistência e caos/liberdade. Então, a política não é simplesmente uma assimetria de poder. $\mathrm{O}$ controle ou a dominação nem sempre podem ser totalmente seguros ou tranquilos, em parte em virtude da agência. Entende-se que a abordagem do ciclo de políticas não pretende minimizar ou subestimar os efeitos ou impactos das políticas, mas problematizar todo o processo subjacente à proposta da abordagem (Ball, 1994).

\section{RESULTADOS E DISCUSSÕES}

A partir da organização e tabulação dos dados, estes foram analisados à luz da fundamentação teórica apresentada anteriormente e com base na análise de conteúdo (Moraes, 1999). Foram organizados em seis categorias de análise, quais sejam: as secretarias municipais de educação da pesquisa, a oferta de atividades musicais nas escolas, as atividades musicais existentes nas escolas, a promoção de concursos públicos para professores de música, a presença de professores de música nas escolas e os profissionais que desenvolvem atividades musicais nas escolas.

\section{AS SECRETARIAS MUNICIPAIS DE EDUCAÇÃO DA PESQUISA}

Os dados de identificação informados nos questionários permitiram identificar quantas e quais secretarias municipais de educação do Rio Grande do Sul retornaram o questionário respondido. Dos 497 municípios existentes no estado, 270 responderam à pesquisa, o que soma 54,32\%.

Na época da coleta dos dados (2015), o número total de escolas existentes no estado somava 2.500, das quais foram obtidas informações de 1.612 escolas — por meio das secretarias municipais de educação. Ao todo, as informações apresentadas nesta pesquisa perfazem 64,48\% das escolas públicas municipais do Rio Grande do Sul, o que se apresenta com um bom índice de retorno em se tratando de pesquisa, pois, de acordo com Marconi e Lakatos (2005), questionários que são enviados para entrevistados em pesquisas alcançam em média 25\% de devolução. Os resultados apresentados e as discussões deste artigo baseiam-se neste retorno.

\section{A OFERTA DE ATIVIDADES MUSICAIS NAS ESCOLAS}


Com base nos dados da pesquisa, constatou-se que 219 secretarias municipais de educação oferecem a música nas escolas de sua rede de ensino. Esse número perfaz $81,11 \%$ do total de respondentes. É um índice significativo, pensando-se na quantidade de escolas que ofertam a música. Todavia, não é possível fazer uma análise abrangente, pois esse dado relaciona-se aos 270 municípios, entre os 497 existentes no estado.

Para aprofundar a análise desse dado, seria possível pensar que o não retorno dos questionários das 227 das secretarias municipais de educação — que na soma com os 270 questionários retornados resulta 497, ou seja, o número de municípios e de secretarias municipais de educação do Rio Grande do Sul — pode ser justificado pela não oferta de atividades musicais nas escolas das redes de ensino das secretarias não respondentes. Se esse for o modo de analisar, então o percentual diminui para 44,04\%.

Partindo-se deste último número, ou seja, 44,04\%, pode-se considerar um baixo índice de retorno. Corrobora a análise o fato de existir no Brasil, desde o ano de 2008, uma legislação nacional que dispõe sobre a obrigatoriedade da música na educação básica — lei n.11.769/2008. Essa lei tem abrangência nacional e, portanto, deveria ser cumprida em todos os estados e municípios do país.

Esse dado é preocupante em se tratando da inserção da música nas escolas do Rio Grande do Sul. Como análise, pode-se pensar na perspectiva do contexto da prática, proposto na abordagem do ciclo de políticas. Conforme Bowe et al. (1992), é no contexto da prática que a política está sujeita à interpretação e recriação. É nesse contexto que a política produz efeitos que podem representar mudanças e transformações. Nesse sentido e, concordando com os autores, observa-se que a legislação para a inserção da música nas escolas do Rio Grande do Sul não foi simplesmente "implementada", mas esteve sujeita à interpretação (Bowe et al., 1992). A partir da análise dos dados, observou-se que diversas secretarias municipais de educação recriaram a lei, entendendo que a obrigatoriedade para a educação básica seja a presença da arte - particularmente as artes visuais ou, até, a educação artística, extinta com a LDB n. 9.394/1996 —, não a música. Desse modo, o que pensam e o que acreditam os profissionais que têm papel ativo e primordial no processo de interpretação e reinterpretação das políticas educacionais - nesse caso, os gestores das secretarias municipais de educação, para o cumprimento da lei federal n. 11.769/2008 — traz implicações diretas para o sucesso ou insucesso no processo de implementação das políticas educacionais.

\section{AS ATIVIDADES MUSICAIS EXISTENTES NAS ESCOLAS}

As atividades musicais existentes nas escolas da rede pública municipal do Rio Grande do Sul são diversificadas. As respostas para esse tópico foram encaminhadas por $27,77 \%$ das secretarias municipais de educação, não havendo retorno de $72,23 \%$ dos questionários. De acordo com as respostas, de modo geral constatou-se que existem atividades musicais como canto coral, bandas, aulas de instrumentos musicais, aulas de música dentro da disciplina de educação artística, música integrada às outras disciplinas, atividades esporádicas de música para preparação de festividades, promoções eventuais de festivais de música ou amostras de arte com 
música e aulas de música como disciplina específica - separada da disciplina de educação artística. A Tabela 1 apresenta as atividades musicais e suas incidências.

Além dessas atividades, em 31\% das respostas das secretarias municipais de educação foram encontradas outras modalidades de oferta para as atividades musicais nas escolas. Esses 31\% dividem-se em oficinas extracurriculares de música, aulas de instrumentos musicais, atividades musicais oportunizadas pelo Programa Mais Educação, ${ }^{1}$ banda marcial, festivais de música e apresentações públicas, aulas na educação infantil e séries iniciais, atividades musicais oportunizadas pelo Programa Escola Aberta $^{2}$ e oficinas de música para alunos e professores. A Tabela 2 apresenta as outras atividades musicais existentes nas escolas.

Uma análise sobre as atividades musicais existentes nas escolas da rede pública municipal de ensino do Rio Grande do Sul pode ser feita com base em

\section{Tabela 1 - As atividades musicais existentes nas escolas da rede pública municipal de ensino}

\begin{tabular}{l|c}
\hline Tipo de Atividade Musical & $\%$ \\
\hline Atividades extracurriculares, como canto coral, bandas, aulas de instrumentos musicais & 58,51 \\
\hline Aulas de música dentro da disciplina de educação artística & 39,25 \\
\hline Atividades com música, integradas às outras disciplinas & 39,25 \\
\hline Atividades esporádicas de música para preparação de festividades & 27,77 \\
\hline Promoções eventuais de festivais de música ou amostras de artes com música & 20,74 \\
\hline Aulas de música como disciplina específica - separada da disciplina de educação artística & 15,95 \\
\hline
\end{tabular}

Fonte: Banco de dados da pesquisa.

Elaboração da autora.

1 O Programa Mais Educação foi instituído pela portaria interministerial n. 17/2007 e regulamentado pelo decreto n. 7.083/2010. Foi uma estratégia do Ministério da Educação (MEC) no Brasil para ampliar a jornada escolar e a organização curricular na perspectiva da educação integral. As escolas das redes públicas de ensino estaduais, municipais e do Distrito Federal fazem a adesão ao programa e, de acordo com o projeto educativo em curso, optam por desenvolver atividades nos macrocampos de acompanhamento pedagógico; educação ambiental; esporte e lazer; direitos humanos em educação; cultura e artes; cultura digital; promoção da saúde; comunicação e uso de mídias; investigação no campo das ciências da natureza e educação econômica. As atividades musicais são possibilidades de atividades no macrocampo cultura e artes.

2 Programa em cooperação técnica entre o MEC e a Organização das Nações Unidas para a Educação, a Ciência e a Cultura (UNESCO): objetiva contribuir para a melhoria da qualidade da educação, a inclusão social e a construção de uma cultura de paz por meio da ampliação da integração entre escola e comunidade; ampliação das oportunidades de acesso à formação para a cidadania e redução de violências na comunidade escolar. Visa proporcionar aos alunos da educação básica de escolas públicas e às suas comunidades espaços alternativos nos fins de semana para o desenvolvimento de atividades de cultura, esporte, lazer, geração de renda, formação para a cidadania e ações complementares às de educação formal. As atividades musicais são fortemente desenvolvidas nesse programa. 
conceitos da educação musical, considerando-se o que postula Kraemer (2000). De acordo com o autor, a educação musical dar-se-á na relação entre as pessoas e as músicas. Se a análise se der levando em consideração os 58,51\% dos respondentes que revelaram os tipos de atividades musicais que existem, como participação em grupos de canto coral, bandas, entre outras atividades extracurriculares - que não a música como disciplina inserida no currículo -, pode-se considerar que a educação musical esteja ocorrendo nesses municípios, servindo para o cômputo da existência da música nas escolas da rede pública municipal de ensino no Rio Grande do Sul.

Porém outras duas ponderações podem ser feitas. Uma delas, relativa à educação musical, e a outra que remete, novamente, à abordagem do ciclo de políticas. Quanto à educação musical, se há atividades musicais nas escolas, envolvendo estudantes e músicas, sim, a resposta será afirmativa: a educação musical está presente nas escolas! Entretanto, é importante pensar também que, se a música na escola ocorrer predominantemente como atividade extracurricular, um questionamento poderá ser feito: Quando será possível, efetivamente, inserir a música nas escolas de modo amplo, possibilitando interlocuções com as demais áreas e, assim, contribuindo efetivamente com o processo de educação escolar? Entende-se a importância de a música encontrar-se em diversos tempos e espaços da escola. Mas entende-se também que é importante estabelecê-la como uma das disciplinas integrantes do currículo da educação básica. E mesmo que, no contexto da prática, cada vez mais seja possível esse estabelecimento, nada garante a continuidade dessa existência, considerando-se a longa história da educação musical no Brasil - apresentada no início deste artigo - com suas idas e vindas, inserções e exclusões, desde o século XIX.

Essa perspectiva de análise liga-se à segunda ponderação. Se a música ficar restrita às atividades extracurriculares da escola, corre-se o risco de que ela fique apenas nesse tempo e espaço escolar - novamente, pois essa situação já ocorreu na longa história da educação musical escolar no Brasil. Desse modo, o contexto

Tabela 2 - Outras atividades musicais existentes nas escolas da rede pública municipal de ensino

\begin{tabular}{l|c}
\hline Tipo de Atividade Musical & $\%$ \\
\hline Oficinas extracurriculares de música & 42 \\
\hline Aulas de instrumentos musicais & 31 \\
\hline Atividades musicais no Programa Mais Educação & 24 \\
\hline Banda marcial & 21 \\
\hline Festivais de música e apresentações públicas & 11 \\
\hline Aulas na educação infantil e séries iniciais & 5 \\
\hline Atividades musicais no Programa Escola Aberta & 2 \\
\hline Oficinas de música para alunos e professores & 1 \\
\hline
\end{tabular}

Fonte: Banco de dados da pesquisa.

Elaboração da autora. 
da prática - caracterizado pela paulatina legitimação da música como extracurricular - propiciará a gradual ausência da música como integrante do currículo, consubstanciando-se como algo fora da escola. Assim, haverá efeitos - o que se encontra no contexto dos efeitos (Bowe et al.,1992) - fazendo com que novamente seja retirada a obrigatoriedade da música nas escolas. Observa-se, portanto, que, mesmo que de um modo, conceitualmente estejamos constatando a presença da música nos contextos das escolas da rede pública municipal do Rio Grande do Sul, há que se fazer essa análise com muita prudência.

Ainda, é importante salientar que toda essa análise baseia-se em 27,77\% dos respondentes que apontaram as atividades musicais em suas redes de ensino. Em 72,23\% não houve respostas, o que pode remeter, como analisado anteriormente - no que tange à oferta de atividades musicais nas escolas da rede pública municipal de ensino - , que a maioria das secretarias municipais de educação do Rio Grande do Sul não oferta a música em sua rede de ensino, outro dado que revela o descumprimento da legislação nacional em educação.

\section{A PROMOÇÃO DE CONCURSOS PÚBLICOS PARA PROFESSORES DE MÚSICA}

A promoção de concursos públicos para o provimento de cargos de professores de música nas escolas públicas municipais do Rio Grande do Sul foi um dos itens desta pesquisa, que se apresentou com índices bastante baixos. A análise pode ser feita tanto considerando os questionários que retornaram com essa informação quanto os que não apresentaram esse dado.

Em uma primeira análise, entre as 270 secretarias municipais de educação que retornaram os questionários, o índice de realização de concursos apontado foi de 18,14\%, ou seja, 49 municípios realizaram concursos para professores de música no Rio Grande do Sul. As demais 214 secretarias (79,25\%) responderam não terem realizado concurso. Sete secretarias $(2,59 \%)$ não responderam a essa questão. A Tabela 3 sintetiza os dados sobre a promoção de concursos públicos para professores de música.

O índice de 18,14\% é bastante baixo, principalmente se for levado em consideração que há uma legislação no Brasil que dispõe sobre a obrigatoriedade da música na escola, caracterizada pela lei n. 11.769/2008. Corrobora o fato de que essa lei já deveria estar em vigor desde 2011, e a coleta dos dados desta pesquisa ter sido realizada em 2015. Ou seja, mesmo após quatro anos do prazo final da lei entrar em vigor, ela ainda não tem sido cumprida.

Tabela 3 - Promoção de concursos públicos para professores de música

\begin{tabular}{l|c}
\hline Promoção dos Concursos & $\%$ \\
\hline Municípios que não promoveram concursos públicos para professores de música & 79,25 \\
\hline Municípios que promoveram concursos públicos para professores de música & 18,14 \\
\hline Municípios que não responderam à questão & 2,59 \\
\hline
\end{tabular}

Fonte: Banco de dados da pesquisa.

Elaboração da autora. 
Mas o quadro agrava-se ainda mais se a análise for ampliada, quando se considera a totalidade de municípios do Rio Grande do Sul, ou seja, 497. Nesse caso, temos 49 municípios que realizaram concurso $(18,14 \%)$ e 441 que não realizaram, o que perfaz $88,73 \%$ do total. Esse número de 441 origina-se das respostas negativas quanto aos concursos por parte de 214 secretarias municipais de educação que retornaram o questionário, somadas às 227 secretarias que não o retornaram. Isso pode ser um indício da não existência da música nas escolas de suas redes de ensino e, por consequência, da não realização de concursos públicos para o ingresso de professores de música. Se quisermos aprofundar mais a análise, então o número de 441 pode ser acrescido de 7 (questionários que não continham a resposta a essa questão), resultando em 448 municípios $(90,14 \%)$ que não realizaram concursos públicos para o provimento de cargos de professores de música em suas redes de ensino. Os 49 municípios que promoveram os concursos, nesse caso, perfazem $9,85 \%$ do total. A análise ampliada da situação da realização desses concursos encontra-se sintetizada na Tabela 4.

Além da análise já apresentada, remetendo à abordagem do ciclo de políticas, considerando-se os contextos do texto político e o contexto da prática, que podem resultar em modificações na legislação e, assim, ser retirada a obrigatoriedade da música nas escolas, há que se considera, também a dinâmica necessária à realização de concursos públicos nos municípios brasileiros, sejam eles da natureza que forem, até mesmo para professores de música. De acordo com o item IV, artigo 21 da lei n. 6.448, de 11 de outubro de 1977, compete à Câmara Municipal, com a sanção do prefeito, criar, alterar e extinguir cargos públicos, fixando-lhes os vencimentos (Brasil, 1977a). Nesse sentido, para que um município possa realizar concurso público para o provimento de cargos de professor de música, é fundamental que, primeiramente, os cargos existam. Entende-se que, na maioria dos municípios do Rio Grande do Sul, esses cargos ainda não existem. Desse modo, o caminho para a realização de concursos para professores de música é bastante longo, pois a trajetória da criação de leis é lenta no Brasil, e o quadro que se apresenta no Rio Grande do Sul não é diferente.

\section{A PRESENÇA DE PROFESSORES DE MÚSICA NAS ESCOLAS}

Considerando-se os 49 municípios - entre os 497 - que realizaram concursos para professores de música, observou-se que a maioria os realizou após o ano de 2011, quando findou o prazo para a implantação da lei n. 11.769/2008, que dispões sobre a obrigatoriedade da música nas escolas. Dos municípios que realizaram concursos, 22 (44,89\%) informaram tê-lo realizado após o ano de

Tabela 4 - Análise ampliação da promoção de concursos públicos para professores de música

\begin{tabular}{l|c}
\hline Promoção dos Concursos & $\%$ \\
\hline Municípios que não promoveram concursos públicos para professores de música & 90,14 \\
\hline Municípios que promoveram concursos públicos para professores de música & 9,85 \\
\hline
\end{tabular}

Fonte: Banco de dados da pesquisa.

Elaboração da autora. 
2011. Outros 12 municípios $(24,48 \%)$ responderam já ter promovido concursos para professores de música antes do ano de 2008 . O panorama completo sobre a realização de concursos públicos para professores de música nos 49 municípios que informaram ter realizado concurso é apresentado na Tabela 5.

Desses municípios que realizaram concursos, houve o ingresso de aproximadamente 71 professores de música nas redes públicas municipais do Rio Grande do Sul. Esse ingresso deu-se de diferentes modos nos municípios. Alguns contrataram apenas um professor, outros efetuaram o contrato com mais de um professor de música. A Tabela 6 apresenta os ingressos dos professores de música por meio de concursos públicos no Rio Grande do Sul.

É importante esclarecer que algumas secretarias municipais de educação deixaram de informar o número de professores que ingressaram em suas redes públicas de ensino. Desse modo, alguns desses dados não são aqui apresentados.

\section{OS PROFISSIONAIS QUE DESENVOLVEM ATIVIDADES MUSICAIS NAS ESCOLAS}

Como explicado anteriormente, apesar da não realização de concursos públicos para o provimento de cargo de professor de música por parte da maioria

Tabela 5 - Anos de realização dos concursos públicos para professores de música pelos municípios

\begin{tabular}{l|c}
\hline Realização & $\%$ \\
\hline Municípios que promoveram concursos públicos para professores de música após 2011 & 44,89 \\
\hline Municípios que promoveram concursos públicos para professores de música antes de 2008 & 24,48 \\
\hline Municípios que promoveram concursos públicos para professores de música em 2011 & 18,36 \\
\hline Municípios que promoveram concursos públicos para professores de música em 2010 & 6,12 \\
\hline Municípios que promoveram concursos públicos para professores de música em 2008 & 2,04 \\
\hline
\end{tabular}

Fonte: Banco de dados da pesquisa.

Elaboração da autora.

Tabela 6 - Ingresso de professores de música por meio de concursos públicos no Rio Grande do Sul

\begin{tabular}{l|c|c}
\hline Realização & Número de Municípios & $\%$ \\
\hline Ingresso de 1 professor de música & 19 & 38,77 \\
\hline Ingresso de mais de 5 professores de música & 4 & 8,16 \\
\hline Ingresso de 3 professores de música & 4 & 8,16 \\
\hline Ingresso de 2 professores de música & 3 & 6,12 \\
\hline Ingresso de 5 professores de música & 2 & 4,08 \\
\hline Ingresso de 4 professores de música & 1 & 2,04 \\
\hline
\end{tabular}

Fonte: Banco de dados da pesquisa.

Elaboração da autora. 
dos municípios, muitas secretarias municipais de educação do Rio Grande do Sul informaram que desenvolvem atividades musicais nas escolas de suas redes de ensino. Essa informação deve-se ao fato de a educação musical estar sendo trabalhada por diversos profissionais que, muitas vezes, não são professores de música concursados.

Ao serem questionadas sobre quem são os profissionais que atuam com música nas escolas de suas redes de ensino, as secretarias municipais de educação apontaram uma diversidade de profissionais, inclusive professores de música. Nas respostas das secretarias municipais de educação, quanto aos profissionais que atuam com música nas escolas, destacaram-se professores das séries iniciais ou titulares das turmas, oficineiros contratados por meio de empresas para a prestação desse serviço, professores de artes, professores que tocam instrumentos musicais ou têm alguma experiência em educação musical, mas sem formação musical, instrutores de banda e/ou coral, professores que atuam com outras áreas do conhecimento e oficineiros do Programa Mais Educação.

Além desses profissionais, outros também apareceram nas respostas dos questionários. A Tabela 7 apresenta os dados de forma completa a respeito dos pro-

\section{Tabela 7 - Profissionais que desenvolvem atividades musicais nas escolas das redes públicas municipais do Rio Grande do Sul}

\begin{tabular}{l|c}
\hline Profissionais que trabalham com música nas escolas & $\%$ \\
\hline Professores das séries iniciais ou titulares das turmas. & 19,62 \\
\hline Oficineiros contratados através de empresas para a prestação de serviço. & 18,88 \\
\hline Professores de Artes. & 18,14 \\
\hline $\begin{array}{l}\text { Professores que tocam instrumentos musicais ou têm alguma } \\
\text { experiência em educação musical, mas sem licenciatura em música. }\end{array}$ & 15,18 \\
\hline Instrutores de Banda e/ou Coral. & 11,11 \\
\hline Professores que atuam com outras áreas do conhecimento. & 10,37 \\
\hline Oficineiros do Programa “Mais Educação". & 10 \\
\hline Professores e/ou monitores da Educação Infantil. & 6,66 \\
\hline Professores não concursados em música. & 5,18 \\
\hline Professores concursados em música. & 5,18 \\
\hline Voluntários. & 2,96 \\
\hline Professores com licenciatura em música. & 2,96 \\
\hline Professores que atuam através da Secretaria Municipal de Cultura. & 1,11 \\
\hline Licenciandos dos cursos de graduação em música. & 0,37 \\
\hline Professores itinerantes da escola. & 0,37 \\
\hline Professores de dança. & 0,37 \\
\hline Professores contratados como cargos de confiança. & 0,37 \\
\hline Oficineiros do Programa “Escola Aberta”. & 0,37 \\
\hline Oficineiros dos Centros de Referência da Assistência Social (CRAS). & 0,37 \\
\hline
\end{tabular}

Fonte: Banco de dados da pesquisa.

Elaboração da autora. 
fissionais que desenvolvem atividades musicais nas escolas das redes públicas municipais do Rio Grande do Sul.

\section{SÍNTESE E CONSIDERAÇÕES FINAIS}

Após a apresentação dos resultados e da análise dos dados, apresenta-se uma síntese, com vistas a destacar padrões encontrados na pesquisa e as relações existentes entre as categorias identificadas. Pretende-se, assim, apresentar um quadro mais amplo da inserção da música em escolas públicas municipais do Rio Grande do Sul, respondendo ao objetivo desta investigação.

O retorno dos questionários pelas secretarias municipais de educação pode ser analisado de dois modos. Por um lado, o número de respostas foi significativo para a análise dos dados. Por outro lado, no entanto, há que se salientar a problemática do não retorno dos questionários por parte de 227 instituições públicas. Nesse sentido, pode-se considerar a existência do decreto n. 7.724, de 2012 (Brasil, 2012), que regulamenta a lei n. 12.527, de 2011, sobre o acesso às informações no Brasil. Nesse decreto encontra-se expresso, artigo $7^{\circ}$, capítulo III - da Transparência Ativa - , que é dever dos órgãos e entidades promover, independentemente de requerimento, a divulgação em seus sítios na internet de informações de interesse coletivo ou geral por eles produzidas ou custodiadas. O parágrafo $3^{\circ}$ desse decreto especifica, até mesmo, o dever de divulgar estrutura organizacional, competências, legislação aplicável, principais cargos e seus ocupantes, endereço e telefones das unidades, horários de atendimento ao público, programas, projetos, ações, obras e atividades, com indicação da unidade responsável, principais metas e resultados e, quando existentes, indicadores de resultado e impacto. Percebe-se novamente o descumprimento da legislação vigente. Sabe-se que, muitas vezes, os órgãos públicos têm insuficiência de funcionários, resultando em dificuldades na produção e no acesso às informações, por não existir pessoal em número suficiente para a elaboração das respostas requeridas. Mas, de todo modo, é outro dado que revela o não cumprimento da legislação vigente.

Em se tratando da oferta de atividades musicais nas escolas, se for analisada superficialmente, pode-se dizer que as secretarias municipais de educação do Rio Grande do Sul estão ofertando a música em seus tempos e espaços. Nesse caso, a legislação (Brasil, 2008) está sendo cumprida. Mas, se a análise for mais abrangente e se forem consideradas as Diretrizes Nacionais para a Operacionalização do Ensino de Música na Educação Básica, cujo parecer e o projeto de resolução foram aprovados pela Câmara de Educação Básica (CEB) do CNE, o cumprimento não se está dando adequadamente. Vale salientar, ainda, com base nas diretrizes, que compete às secretarias de educação estabelecer outras ações para promover a formação e a prática de docentes no ensino de música, identificando "em seus quadros de magistério e de servidores, profissionais vocacionados que possam colaborar com o ensino de Música nas escolas, incluindo-os nas atividades de desenvolvimento profissional na área de música" (Brasil, 2013, p. 9). Adicionalmente, as redes de ensino devem, 
também, "promover cursos de formação continuada sobre o ensino de Música para professores das redes de escolas da Educação Básica; [e] apoiar a formação dos professores e dos demais profissionais da educação em cursos de segunda licenciatura em Música" (Brasil, 2013, p. 9). Nos questionários respondidos não foram apontadas iniciativas nesse sentido por parte das secretarias municipais de educação no Rio Grande do Sul.

Um aspecto peculiar a ser analisado diz respeito às atividades musicais existentes nas escolas. Esses dados estão em sintonia com a análise apresentada anteriormente, relativa à oferta de atividades musicais nas escolas. Em sua maioria, a música está presente nas escolas por meio de atividades que não as aulas de música no currículo. Muitas vezes são atividades musicais extracurriculares desenvolvidas por professores não pertencentes aos quadros de professores das escolas, vinculadas a projetos, até mesmo momentâneos, que podem ser finalizados de acordo com as gestões governamentais. São atividades, em geral, que se caracterizam como programas de governo, e não como programas de estado. Com índices menos elevados, foi encontrada a oferta de aulas de música como disciplina específica, separada da educação artística ou de outras atividades.

A realização dos concursos públicos para professores de música é um item que também merece reflexão. Novamente se apresentou o descumprimento da legislação. Deve-se destacar, nas Diretrizes Nacionais para a Operacionalização do Ensino de Música na Educação Básica, que uma das atribuições das secretarias é a de "realizar concursos específicos para a contratação de licenciados em Música" (Brasil, 2013, p. 9). Outra ausência de ações nesse sentido e de descumprimento da legislação foram verificadas nesta pesquisa. Como consequência da não realização de concursos, as últimas categorias de análise - presença de professores de música nas escolas e profissionais que desenvolvem atividades musicais nas escolas - relacionam-se. O número de professores concursados atuantes nas escolas públicas municipais do Rio Grande do Sul é bastante pequeno. E quem efetivamente acaba desenvolvendo esse tipo de atividade são os professores de outras áreas do conhecimento, ou mesmo profissionais que não os da escola, mas oriundos de diversos projetos.

Ao finalizar esta pesquisa, que objetivou investigar a presença da música em escolas públicas municipais do Rio Grande do Sul, constou-se a realidade da música em suas escolas, bem como a relevância do referencial teórico utilizado. A concepção de educação musical de Kraemer auxiliou no entendimento de como a música se insere nas escolas, ao passo que a abordagem do ciclo de políticas balizou a análise da política em vigor.

Entende-se que os resultados desta investigação, bem como os dados de outras pesquisas que têm sido empreendidas no Rio Grande do Sul e no Brasil, poderão subsidiar macro e microanálises das políticas em educação musical no país, assim como fundamentar e ampliar a construção de políticas públicas para a implementação da música nas escolas brasileiras. A problematização que a abordagem do ciclo das políticas propõe, em interlocução com os conceitos de educação musical 
de Kraemer (2000), podem auxiliar no aprofundamento dessas análises sobre a legislação para a inserção da música na educação básica.

Por fim, aponta-se a necessidade do conhecimento e compreensão da legislação existente por parte das secretarias de educação, a fim de que seja efetivamente cumprida a lei da inserção da música nas escolas e de toda a legislação em educação vigente no Brasil.

\section{REFERÊNCIAS}

Ahmad, L. A. S. Música no ensino fundamental: a situação de escolas municipais de Santa Maria/RS. Dissertação (Mestrado em Educação) — Programa de Pós-Graduação em Educação, Universidade Federal de Santa Maria, Santa Maria, 2011.

Babbie, E. Métodos de pesquisas de survey. Belo Horizonte: Editora da UFMG, 1999.

BALL, S. J. Educational reform: a critical and post structural approach. Buckingham: Open University Press, 1994.

BowE, R. et al. Reforming education and changing schools: case studies in policy sociology. London: Routledge, 1992.

Brasil. Lei n. 5.692, de 11 de agosto de 1971. Fixa as Diretrizes e Bases da Educação para o Ensino de $1^{\circ}$ e $2^{\circ}$ graus, e dá outras providências. Diário Oficial da União, Brasília, DF, 12 ago. 1971. Disponível em: <http://www.planalto.gov.br/CCIVIL_03/leis/L5692. htm>. Acesso em: 29 jan. 2016.

. Conselho Federal de Educação. Parecer n. 1.284, de 9 de agosto de 1973. Fixa conteúdos mínimos e duração do curso de Educação Artística. Brasília, DF, Secretaria de Ensino de Primeiro e Segundo Graus, 1973.

.Câmara dos Deputados. Lei n. 6.448, de 11 de outubro de 1977. Dispõe sobre a organização política e administrativa dos Municípios dos Territórios Federais, e dá outras providências. Diário Oficial da União, Brasília, DF, 13 out. 1977a. Disponível em: <http://www2.camara.leg.br/legin/fed/lei/1970-1979/lei-6448-11-outubro-1977366388-normaatualizada-pl.pdf $>$. Acesso em: 29 jan. 2016.

. Conselho Federal de Educação. Parecer n. 540/77, de 10 de fevereiro de 1977, do CFE. Sobre o tratamento a ser dado aos componentes curriculares previstos no art. $7^{\circ}$ da lei 5.692/71. Documenta n. 195, Rio de Janeiro, fev. 1977b. Disponível em: <http://www.histedbr.fe.unicamp.br/navegando/fontes_escritas/7_Gov_Militar/ parecer\%20n.\%20540-1977\%20sobre\%20o\%20tratamento\%20a\%20ser\%20dado\%20 aos\%20comp\%20curriculares.pdf >. Acesso em: 29 jan. 2016.

. Lei n. 9.394, de 20 de dezembro de 1996. Estabelece as Diretrizes e Bases da Educação Nacional. Diário Oficial da União, Brasília, DF: 23 dez. 1996. Disponível em: <http://www.planalto.gov.br/ccivil_03/LEIS/L9394.htm>. Acesso em: 29 jan. 2016.

. Lei n. 11.769, de 18 de agosto de 2008. Altera a lei n. 9.394/96, para dispor sobre a obrigatoriedade do ensino de música na educação básica. Diário Oficial da União, Brasília, DF: Seção 1, 2008. Disponível em: <http://www.planalto.gov.br/ ccivil_03/_ato2007-2010/2008/lei/111769.htm>. Acesso em: 27 jan. 2016. 
Brasil. Decreto n. 7.083, de 27 de janeiro de 2010. Dispõe sobre o Programa Mais Educação. Diário Oficial da União, Brasília, DF, jan. 2010. Disponível em: <http:// www.planalto.gov.br/ccivil_03/_ato2007-2010/2010/decreto/d7083.htm>. Acesso em: 29 out. 2017.

. Casa Civil. Subchefia de Assuntos Jurídicos. Decreto n. 7.724, de 16 de maio de 2012. Regulamenta a lei n. 12.527, de 18 de novembro de 2011, que dispõe sobre o acesso a informações previsto no inciso XXXIII do caput do art. $5^{\circ}$, no inciso II do $\S 3^{\circ}$ do art. 37 e no $\S 2^{\circ}$ do art. 216 da Constituição. Diário Oficial da União, Brasília, DF: 16 maio 2012. Disponível em: <http://www.planalto.gov.br/ccivil_03/_ato20112014/2012/decreto/d7724.htm>. Acesso em: 28 jan. 2016.

. Conselho Nacional de Educação. Câmara de Educação Básica. Parecer n. 12, de 4 de dezembro de 2013, do CNE. Diretrizes Nacionais para a Operacionalização do Ensino de Música na Educação Básica. Brasília, DF, dez. 2013. Disponível em: <http:// portal.mec.gov.br/index.php?option $=$ com_docman\&view=download\&alias $=14875$ pceb012-13\&category_slug=dezembro-2013-pdf\&Itemid=30192 >. Acesso em: 29 out. 2017.

Cohen, L.; Manion, L. Research methods in education. 4. ed. London: Routledge, 1994. Del Ben, L. M. Um estudo com escolas da rede estadual de ensino básico de Porto Alegre-RS: subsídios para a elaboração de políticas de educação musical. Musica Hodie, Goiânia: UFG, v. 5, n. 2, p. 65-89,2005. Disponível em: <http://www.musicahodie.mus. br/5_2/musica_hodie_5_2_artigo_5.pdf>. Acesso em: 5 fev. 2015.

Dinız, L. N. Música na educação infantil: um survey com professoras da rede municipal de ensino de Porto Alegre-RS. Dissertação (Mestrado em Música) - Programa de PósGraduação Mestrado e Doutorado em Música, Universidade Federal do Rio Grande do Sul, Porto Alegre, 2005.

Fusari, M.F. R.; Ferraz, M.H. C.T. Arte na educação escolar. São Paulo: Cortez, 1992. Hentsch ke, L.; Oliveira, A. A educação musical no Brasil. In: Hentsch ke, L. (Org.). Educaşão musical em países de linguas neolatinas. Porto Alegre: Editora da UFRGS, 2000. p. 47-64.

Kraemer, R.-D. Dimensões e funções do conhecimento pedagógico-musical. Em Pauta, Porto Alegre: UFRGS, v. 11, n. 16/17, p. 50-73, abr./nov. 2000.

Laville, C.; Dionne,J.A construção do saber: manual de metodologia da pesquisa em ciências humanas. Porto Alegre: Artes Médicas Sul; Belo Horizonte: Editora UFMG, 1999.

Lemos Júnior, W. História da educação musical e a experiência do canto orfeônico no Brasil. EccoS-Revista Cientifica, São Paulo:UNINOVE, n.27,p.67-80,jan./abr.2012.Disponível em: <http://www.redalyc.org/pdf/715/71523347005.pdf >. Acesso em: 5 fev. 2015.

Marconi, M. A.; Lakatos, E. M. Fundamentos de metodologia cientifica. 6. ed. São Paulo: Atlas, 2005.

Moraes, R. Análise de conteúdo. Educação, Porto Alegre: PUC-RS, ano XXII, n. 37, p. 7-31, mar. 1999.

Penna, M. Professores de música nas escolas públicas de ensino fundamental e médio: uma ausência significativa. Revista da ABEM, Porto Alegre: ABEM,v.7, p.7-19, set. 2002. 
Penna, M. A dupla dimensão da política educacional e a música na escola: I analisando a legislação e os termos normativos. Revista da ABEM, Porto Alegre: ABEM, v. 10, p. 19-28, mar. 2004a.

. A dupla dimensão da política educacional e a música na escola: II da legislação à prática escolar. Revista da ABEM, Porto Alegre: ABEM, v. 11, p. 7-16, set. $2004 \mathrm{~b}$.

Queiroz, L. R. S. Música na escola: aspectos históricos da legislação nacional e perspectivas atuais a partir da lei 11.769/2008. Revista da ABEM, Londrina: ABEM, v. 20, n. 29, p. 23-38, jul./dez. 2012.

Queiroz, L. R. S.; Penna, M. Políticas públicas para a educação básica e suas implicações para o ensino de música. Educação, Santa Maria: UFSM, v. 37, n. 1, p. 91-106, jan./abr. 2012.

ReQUião, L. Música nas escolas: mercadoria ou formação humana? Educação: teoria e prática, Rio Claro: UNESP, v. 23, n. 43, p. 169-181, maio/ ago. 2013. Disponível em: <http://educa.fcc.org.br/pdf/eduteo/v23n43/v23n43a11.pdf>. Acesso em: 4 fev. 2015. Santos, R. M. S. Música, a realidade nas escolas e políticas de formação. Revista da ABEM, Porto Alegre: ABEM, v. 12, p. 49-56, mar. 2005.

SouzA, J. V. et al. A música na escola. In: . O que faz a música na escola? Concepções e vivências de professores do ensino fundamental. Porto Alegre: UFRGS, nov. 2002. p. 17-37 (Série Estudos).

Wolffendüttel, C. R. Ensino de música na educação básica: uma investigação em escolas públicas do Rio Grande do Sul. Congresso da Anprom, 21., 2011, Uberlândia. Anais... Uberlândia: ANPPOM, 2011, p. 335-340.

. A inserção da música em projetos político pedagógicos da educação básica. Curitiba: Prismas, 2014.

Wolffenbüttel, C. R.; Silva, P. C. O ensino de música no litoral do Rio Grande do Sul: uma pesquisa sobre educação musical em escolas públicas municipais. ENCONTRO Regional Sul da Abem, 16., 2014, Blumenau.Anais... Blumenau: ABEM,2014, p. 1-12.

\section{SOBRE A AUTORA}

Cristina Rolim Wolffenbüttel é doutora em educação musical pela Universidade Federal do Rio Grande do Sul (UFRGS). Professora da Universidade Estadual do Rio Grande do Sul (UERGS).

E-mail: cristina-wolffenbuttel@uergs.edu.br

Recebido em 3 de maio de 2016

Aprovado em 21 de junho de 2016 